\title{
ADR evaluation of screening colonoscopies during 2016-2017 in a private health clinic in Peru
}

\section{(ㄷ)(1) $\odot$}

\author{
Author \\ Julio F. León Moreno \\ Institution \\ Instituto de Enfermedades Digestivas, Department of \\ Gastroenterology, Clínica Internacional, Lima, Perú \\ submitted 6.2.2018 \\ accepted after revision 14.5.2018 \\ Bibliography \\ DOI https://doi.org/10.1055/a-0672-1045 | \\ Endoscopy International Open 2018; 06: E1304-E1309 \\ (c) Georg Thieme Verlag KG Stuttgart · New York \\ ISSN 2364-3722 \\ Corresponding author \\ Julio F. León Moreno, MD, Instituto de Enfermedades \\ Digestivas, Department of Gastroenterology, Clínica \\ Internacional, Av. Guardia Civil 421 - 433, San Borja, Lima \\ 41, Perú \\ Fax: +51 16196161 \\ juliolm58@hotmail.com
}

\section{ABSTRACT}

Background and study aims High-quality colonoscopy is fundamental for preventing colorectal cancer (CRC). The adenoma detection rate (ADR) is a key colonoscopy quality measure. The aim of this study was to establish the screening colonoscopy ADR of a tertiary referral center in Peru, identify the relationship between the ADR and patient age, sex and the colonoscopist, and determine the endoscopic and histopathological characteristics of the lesions found.

Patients and methods $A$ retrospective observational longitudinal study was undertaken between January 2016 and June 2017.

Results Eight colonoscopists performed screening colonoscopies on 620 patients scoring $\geq 6$ points on the Boston Bowel Preparation Scale (BBPS); cecal intubation was complete in 595 patients (cecal intubation rate [CIR] 95.9\%). The overall ADR was $29.7 \%$ (females $25.4 \%$, males $33.1 \%$, $P=0.040,95 \% \mathrm{Cl})$. The ADR colonoscopist range was $25.0 \%$ to $34.4 \%$. The highest $\operatorname{ADR}(41.2 \%, P=0.013,95 \% \mathrm{Cl})$ was for patients aged 65 to 75 years. Adenoma colon locations were: left $49 \%$, transverse $21.6 \%$ and right $29.4 \%$. Adenoma dysplasia grades: low $98 \%$, high $2 \%$. Sixty-three percent of the lesions were $5 \mathrm{~mm}$ to $10 \mathrm{~mm}$. Resections performed: $78.5 \%$ cold biopsy forceps (CBF), $3.4 \%$ cold snare polypectomy (CSP) and $18.1 \%$ endoscopic mucosal resection (EMR).

Conclusions The ADR established was in line with the joint American College of Gastroenterology (ACG)/American Society for Gastrointestinal Endoscopy (ASGE) recommendations and related to patient age and gender but not to the colonoscopist. Colonoscopists should ensure rigorous application of the colonoscopy quality actions. ADR should be evaluated frequently.

\section{Introduction}

Colonoscopy is the principal procedure used for colorectal cancer (CRC) screening in the United States [1] and its use is recommended by the American College of Gastroenterology (ACG) Screening Guidelines [2]. Adenoma detection rate (ADR) is considered to be the most important parameter for evaluating the quality of screening colonoscopy programs, therefore, ADR determination is also beneficial for patients [3].

ADR is defined as the proportion of colonoscopies in which at least one histologically confirmed adenoma is detected and is inversely related to deaths from CRC $[4,5]$. Centers responsible for performing screening colonoscopy programs should use appropriate indicators to monitor the quality of their performance [6], particularly in light of possible significant performance variations among colonoscopists [7].

Colorectal adenomas are considered to be the principal risk factor for development of CRC [8] and failure to detect adenomas during a screening colonoscopy has been related to an increased risk of CRC [1]. Kaminsky MF et al. found that an ADR of less than $20 \%$ is related to a higher risk of developing interval CRC [5] and for each $1 \%$ increase in the ADR there could be a $3 \%$ reduction in interval CRC [4]. Current ADR benchmarks recommended by the ACG/American Society of Gastrointestinal Endoscopy (ASGE) are $25 \%$ for all patients and sex-specific rates of $30 \%$ for males and $20 \%$ for females [1,3]. In addition, ADR 
could be up to $40 \%$ if the screening strategy was initiated with a fecal occult blood test (FOBT) [9].

$A D R$ is dependent on a number of factors, which may be broadly grouped as: patient-specific, relating to the characteristics of each patient, e. g. age, sex, medical history etc.; colonoscopist-specific, relating to the skill and experience of the colonoscopist; and procedural factors, relating to the colonoscopy procedure itself. It is generally accepted that the most important factors affecting ADR are the colonoscopist's skill and experience [5], cecal intubation rate (CIR), and quality of the colonic preparation, using for example the Boston Bowel Preparation Scale (BBPS) [10] as a measure $[9,11]$, allowing sufficient colonoscope withdrawal time to permit detailed inspection of the colonic mucosa and folds. Patient-specific factors and procedural factors (instruments, techniques, technology) are all associated with improved ADR scores [12]. Examples of procedural actions are: liquid aspiration, position changes, use of butyscopolamine, utilization of a shallow-fitting cap in the end of the endoscope [13] and new technologies (e. g. high-resolution or the "third eye" scope). These procedural actions contribute to improved detection of polyps and adenomas $[14,15]$ thereby improving ADR.

The objectives of this study were to: (a) retrospectively establish ADR of the screening colonoscopy program of the Department of Gastroenterology of the Instituto de Enfermedades Digestivas, Clínica Internacional, Lima-Peru (a tertiary referral center) from January 2016 to June 2017, (b) identify the relationship between ADR and patient age and sex and the colonoscopist; and (c) determine endoscopic and the histopathological characteristics of the lesions found.

Clínica Internacional, Lima - Peru is one of the few centers in Peru offering a CRC screening colonoscopy program and this study would provide quality assurance for that program. Given the importance of ADR as a quality measure for reduction of CRC, its actual determination is therefore essential.

\section{Patients and methods}

A longitudinal, observational and retrospective study was performed to evaluate the ADR for patients undergoing CRC screening colonoscopies between January 2016 and June 2017 in the Clínica Internacional, Lima, Peru. The colonoscopies were performed by eight colonoscopists, all specialist gastroenterologists, with similar education and training profiles after first publication of the colonoscopy quality indicators by the ACG/ ASGE Task Force on Quality in Endoscopy (2006), each of whom perform $>400$ colonoscopies annually.

Patients included in the study had undergone screening colonoscopies, were aged 50 years or older, presented with good colonic preparation of BBPS $\geq 6$ points, and in whom cecal intubation had been achieved and for whom completed endoscopic and histopathological data were available. Patients excluded from the study were those with a history (or a family history) of colonic disease either acquired or inherited or with anatomical colonic alterations as a result of previous surgery. The study population initially included 649 patients but 29 failed to present a colonic preparation of BBPS 6 and among the remaining
620 patients, cecal intubation could not be achieved in another 25 , resulting in 595 patients in whom colonoscopies were completed.

Collection and subsequent analysis of data were authorized in July 2017 by the 'Comité de Docencia e Investigación de la Clínica International'. The Data Collection Files were populated with patient age and sex from patient data files and for each colonoscopy the following: colonoscopy and histopathological reports, sedation used, preparation classification as per the BBPS, whether the colonoscopy was completed or not, number of lesions detected, lesion classification as per the Paris Classification, lesion location (in left, right or transverse colon), the resection treatment applied, i.e. cold forceps biopsy (CBF) or cold snare polypectomy (CSP) or endoscopic mucosal resection (EMR), and the histopathological result (adenomas and their grade of dysplasia and other lesions). Each colonoscopist determined appropriate patient preparation depending on the patient's characteristics, with the patient drinking either a 4-L solution of polyethylene glycol (full dose or split dose) or a $90-\mathrm{mL}$ sodium phosphate solution.

Colonoscopies were performed with the patients under conscious sedation using midazolam medium dose $(5 \mathrm{mg}$ ) (in compliance with local regulations and practice) together with meperidine applied intravenously, at the colonoscopist's discretion. White light was used in all the colonoscopies and chromoendoscopy was used as the colonoscopist believed necessary. Cecal intubation was photo documented. Colonoscope withdrawal time was between 7 and 10 minutes and included a double examination view or a detailed inspection of the colonic mucosa and folds of the right colon, with a change of the patient's position at the beginning of the withdrawal to a flat position so as to view the right and transverse colon, then to a leftside position to view the left colon (this was only reported by four of the eight colonoscopists). All of the colonoscopies were performed using Pentax Medical Series 90K endoscopes with EPK-i and EPK-i5000 Video Processors.

The information from each colonoscopy was recorded in Microsoft Excel, descriptive statistical analysis of the variables was performed and frequency plots and chi-squared tests were run to identify any relationship between the variables and the ADR. $A$ value of $P<0.05$ was considered statistically significant and statistical analyses were processed using the IBM SPSS version 22 (Statistical Package for the Social Sciences). ADR was established for each colonoscopist's group of patients by age and sex and then consolidated for all eight colonoscopists.

\section{Results}

ADR results for the 620 patients scoring BBPS $\geq 6$ points were as follows: 595 patients completed cecal intubation (cecal Intubation rate [CIR] 95.9\%) with an overall ADR of $29.7 \%$. The sexspecific ADR was: females $25.4 \%$, males $33.1 \%(P=0.040$, OR: $0.687,95 \% \mathrm{Cl}: 0.479-0.984)$ ( $\triangleright$ Table 1 ). The average age of the 595 patients was 57.6 years \pm 5.9 years and the highest ADR was $41.2 \%(P=0.013$, OR: $0.551,95 \% \mathrm{Cl}: 0.343-0.885)$ for patients in the age band 65 to 75 years ( $>$ Table 2 ). These results indicate the existence of a statistically significant rela- 
tionship between ADR and patient age and sex. ADR by colonoscopist ( $\triangleright$ Table 3 ) ranged from $25.0 \%$ to $34.4 \%$ and there was no relationship between ADR and the colonoscopists ( $P=$ $0.902,95 \% \mathrm{Cl})$.

A total of 531 lesions were found, the sizes of which were: $<5 \mathrm{~mm} 21 \%, 5 \mathrm{~mm}$ to $10 \mathrm{~mm} 63 \%, 11 \mathrm{~mm}$ to $19 \mathrm{~mm} 13 \%$ and $>20 \mathrm{~mm} \mathrm{3 \%}$. Using the Paris Classification, 529 lesions were classified as: type 0 -Is $84.8 \%$, type 0 -Ip $1.3 \%$, type 0 -Ila $13.0 \%$ and type 0 -IIb $0.2 \%$.

Two hundred seventy-six of the lesions (52\%) were not adenomas and were classified as: hyperplastic polyps $48.8 \%$, serrated polyps $1.7 \%$, serrated adenomas $0.75 \%$, and adenocarcinomas $0.75 \%$.

Two hundred fifty-five adenomas were found and the histopathological analysis showed dysplasia grades of: $98 \%$ lowgrade and $2 \%$ high-grade. Colonic locations of the adenomas were: left $49 \%$, transverse $21.6 \%$ and right $29.4 \%$ ( Table 4 ).

Resections performed were: $78.5 \%$ cold biopsy forceps (CBF), $3.4 \%$ cold snare polypectomy (CSP) and $18.1 \%$ endoscopic mucosal resection (EMR).

\section{Discussion}

Two principal patient-specific factors determining prevalence of adenomas are patient age and sex [3]. In this study the ADR was higher in males than in females ( $\triangleright$ Table 1 ) and also higher with increasing patient age ( $\triangleright$ Table 2 ), confirming the results reported by others that there exists a relationship between patient age and sex and ADR $[16,17]$. The ADR result for each colonoscopist ( $\triangleright$ Table 3 ) indicates no relationship between the overall ADR and the colonoscopist and this appears to be at variance with other reports [3]. This variance may be because this study focused on a group of eight colonoscopists all with similar skill and experience and whose training as specialist gastroenterologists had mostly occurred after publication in 2006 of the initial joint ACG/ASGE Task Force on Endoscopy Quality Guidelines [3]. Also, their familiarity with similar types of colonoscopy instruments was an important factor in the colonoscopy procedures underlying the ADR result [18] as was the supervision provided by the center's directors.

The increased attention paid to the ADR measure post-2006 probably focused the attention of the colonoscopists on the underlying colonoscopy quality factors. For example, AbdulBaki $\mathrm{H}$. et al. found a variation between ADR results obtained prior to the introduction of public reporting of colonoscopy quality (ADR 34.3\%) and those obtained once the transition to public reporting was completed (ADR 39.2\%) [19]. The overall ADR result of the current study is reasonably in line with those reported by others for screening colonoscopies, for example: in the United States 35.9\% [20] and in Brazil 27.1\% (females 25.3 $\%$ and males $30.6 \%$ ) [16]. In Peru there were two reports of ADRs for colonoscopies with indications other than screening: $10 \%$ [21] and 27\%. [22]. The variability of these reported ADRs from Peru could be due to a number of factors of which the colonoscopists' skill and experience could be a major one [20]; other factors could be: the number of unsupervised/training/teaching colonoscopies, colonoscopies performed with in-
Table 1 Number of screening colonoscopies and ADR by patient sex.

\begin{tabular}{|l|l|l|}
\hline Patient sex & $\mathbf{n}$ & ADR (\%) \\
\hline Female & 260 & $25.4 \%$ \\
\hline Male & 355 & $33.1 \%$ \\
\hline Total & 595 & $29.7 \%$ \\
\hline
\end{tabular}

$P=0.040$, OR: 0.687 (95\% Cl: $0.479-0.984)$

- Table 2 Number of screening colonoscopies and ADR by patient age.

\begin{tabular}{|l|c|c|}
\hline Patient age & $\mathbf{n}$ & ADR (\%) \\
\hline $50-64$ & 510 & $27.8 \%$ \\
\hline $65-75$ & 85 & $41.2 \%$ \\
\hline Total & 595 & $29.7 \%$ \\
\hline$P=0.013$, OR: $0.551(95 \% \mathrm{Cl}: 0.343-0.885)$ & \\
\hline
\end{tabular}

- Table 3 Number of screening colonoscopies and ADR for eight colonoscopists.

\begin{tabular}{|l|c|l|}
\hline Colonoscopist & $\mathbf{n}$ & ADR (95\% CI) \\
\hline 1 & 8 & $25.0 \%(8.0-58.2)$ \\
\hline 2 & 90 & $34.4 \%(26.8-43.3)$ \\
\hline 3 & 92 & $31.5 \%(23.9-40.6)$ \\
\hline 4 & 109 & $29.4 \%(22.4-37.8)$ \\
\hline 5 & 63 & $27.0 \%(18.3-38.3)$ \\
\hline 6 & 84 & $32.1 \%(24.2-41.6)$ \\
\hline 7 & 108 & $25.0 \%(18.2-33.5)$ \\
\hline 8 & 41 & $29.3 \%(18.7-43.4)$ \\
\hline Total & 595 & $29.7 \%(26.6-33.2)$ \\
\hline$P=0.902,95 \%$ Confidence Interval & \\
\hline
\end{tabular}

- Table 4 Location of adenomas by colonic segment.

\begin{tabular}{|c|c|c|c|c|}
\hline $\begin{array}{l}\text { Number of } \\
\text { adenomas }\end{array}$ & Left & Transverse & Right & Total \\
\hline 1 & 59 & 25 & 34 & 118 \\
\hline 2 & 42 & 21 & 23 & 86 \\
\hline 3 & 18 & 7 & 14 & 39 \\
\hline 4 & 6 & 2 & 4 & 12 \\
\hline $\begin{array}{l}\text { Total } \\
\text { (\% of total) }\end{array}$ & $\begin{array}{l}125 \\
(49 \%)\end{array}$ & $\begin{array}{l}55 \\
(21.6 \%)\end{array}$ & $\begin{array}{l}75 \\
(29.4 \%)\end{array}$ & $\begin{array}{l}255 \\
(100 \%)\end{array}$ \\
\hline
\end{tabular}


dications other than screening, i.e. being higher for follow-up colonoscopies [23]. The importance of the colonoscopist's experience in performing screening program colonoscopies has been found to relate directly to other colonoscopy quality parameters [9]. The colonoscopists in this study also perform colonoscopies in other tertiary referral centers in Lima, Peru and this contributes to improving their individual and collective practice experience and promotes higher ADRs. For example, Do A. et al. in a study of patients in an academic medical center observed that to obtain a reliable evaluation of the ADR by endoscopist it was important to have large sample sizes, e. $g$. 500 colonoscopy procedures, to narrow the confidence interval (CI) when evaluating the ADR [24] and implying that colonoscopy centers are better located in the larger urban population centers.

Other factors affecting the ADR include withdrawal time of the colonoscope, colonic preparation and the degree of thoroughness of the examination of the right colon. These factors were taken into account by the colonoscopists in this study, which most likely positively influenced the final ADR $[3,9,11-$ 14]. Adherence to the BBPS $\geq 6$ [10] for colonic preparation also may have contributed positively to the ADR result in this study [11]. Current literature indicates that adequate colonic preparation would be BBPS $\geq 5$ [10]; however, in the center considered in this study, it was already accepted practice that colonic preparation should be to the level of BBPS $\geq 6$. The patients in this study were in a state of conscious sedation even though the sedation dose was greater than that reported in Performance Indicator of Colonic Intubation (PICI) [25]. None of the procedure reports indicated that colonoscopies had to be suspended because of patient discomfort, nor were there any indications of any interruption to cecal intubation. It is generally accepted that adequate CIR values to be achieved should be $>90 \%$ for general colonoscopies and $>95 \%$ for screening colonoscopies [3,11]. That was achieved for the screening colonoscopies in this study and is probably a reflection of the training and experience of the colonoscopists [9].

To prevent CRC, all colonoscopies should ensure a complete evaluation of the colonic mucosa and complete removal of polyps found. This highlights two critical actions: first, the need for thorough characterization of lesions prior to their excision and second, choice of method for lesion retrieval to ensure complete removal. Distribution by lesion type found in this study, excluding the adenocarcinomas $(0.75 \%$ of the total found), was similar to the findings reported by others [26]. As regards the Paris Classification, a search of the recent research literature did not produce useful Paris Classification data on which to base a comparative discussion of this study's findings, indeed the suitability of the Paris Classification appears to be under scrutiny $[26,27]$.

Of the adenomas found, $51 \%$ were located in the proximal colon, whereas others have reported finding the majority in the distal colon $[9,11,16,18]$. This difference could be due to there being a causal relationship with respect to the personal characteristics of the patient populations sampled, in addition to factors related to the degree of colonic preparation and colonoscopist experience, e.g. methods of examination and eval- uation of the proximal colon [11]. The higher number of adenomas in the left colon could be related to a predominance of the adenoma production pathway (suppressor) that more frequently affects the distal colon [28]. In addition to the $0.75 \%$ of malignant lesions (adenocarcinomas), other polyps or adenomas were detected, i.e. $2.45 \%$ which had high premalignancy potential (serrated polyps and adenomas). Given the relationship between serrated lesions and CRC it is important to correctly characterize all the lesions found and determine their appropriate treatment [29]. Abdeljawad et al. [30] summarized nine studies on sessile serrated lesion detection rates, with one study presenting a detection rate of $13.8 \%$ and eight others ranging from $0.6 \%$ to $5.3 \%$; three of these studies reported detection rates between $0.6 \%$ and $1.7 \%$ which are lower than the detection rate of $2.45 \%$ found in this study. Higher detection rates for serrated lesions observed in other studies could be due to the experience of the reporters in detecting sessile serrated lesions. For example, Abdeljawad et al. reported a detection rate of $8.1 \%$ for 1910 screening colonoscopies by a colonoscopist with an already high detection rate for serrated lesions and an experienced pathologist [30]. Mishra G. et al. commented that "knowledge and familiarity of their appearance are key to the detection of these lesions" [29].

Comparing screening colonoscopy detection rates for sessile serrated lesions in the absence of a generally accepted benchmark is very challenging, particularly because factors that influence the detection rate are numerous, which in turn complicates reconciliation of detection rates from different studies. The British Society of Gastroenterology (BSG) [31] in a 2017 position statement included 17 colonoscopy studies evaluating detection rates for serrated lesions covering the period 2006 to 2014 of which five retrospective studies for screening colonoscopies evaluated detection rates for sessile serrated adenomas $1.4 \%$ to $9 \%$, traditional serrated adenomas $<0.1 \%$ to $2.3 \%$ and serrated polyps $17.5 \%$ to $40 \%$. The BSG's position statement suggested that colonoscopists in assessing "their proximal serrated polyp detection rate might aim for $>5 \%$ " [31].

In summary, the significant variations in detection rates for sessile serrated adenomas are very likely due to a combination of: (a) patient-specific factors, possibly related to, for example, genotypic and phenotypic heterogeneity present in particular populations and related to the risk of suffering CRC; (b) colonoscopy-related factors, such as the type of colonoscopy, (screening or follow-up or other), colonoscopy procedural decisions, (white light, use of magnification etc), the skill and experience of the colonoscopist in the identification and characterisation of these lesions; and (c) confusion over classification of serrated lesions to be considered when evaluating detection rate.

In this study, the most frequent treatment for management of polyps or adenomas was excision with CBF (78.5\% of all lesions found) with the remainder excised with CSP; this was to be expected given that $84 \%$ of the total lesions were $\leq 10 \mathrm{~mm}$ in size. At the time the colonoscopies in this study were performed, the usual practice in various colonoscopy centers in Peru was to use CBF for polyps or adenomas up to $7 \mathrm{~mm}$ and CSP for those between $8 \mathrm{~mm}$ and $9 \mathrm{~mm}$. This provided a good 
safety profile and sample recovery, however, the complete resection rate is lower when compared to that with CSP for lesions between $5 \mathrm{~mm}$ and $7 \mathrm{~mm}$ [32]. This approach was consistent with the then European guidelines (2010) which recommended "the use of either snare or forceps polypectomy for lesions $\geq 5 \mathrm{~mm}$; the use of forceps resection was recommended only for lesions $<5 \mathrm{~mm}$ " [33]. Various studies have evaluated use of $C B F$ in resection of very small polyps observing high retrieval rates of $100 \%$ compared to $39 \%$ to $90.7 \%$ for complete histological resection [34].

Directors of colonoscopy centers and screening program colonoscopists must regularly evaluate ADR and quality actions and parameters that will influence it $[1,9]$, considering for example ADR, patient bowel preparation, withdrawal time, CIR, the number of unsupervised/training colonoscopies, type of sedation, rate of colonoscopic perforations, bleeding rates postpolypectomy, description and characterization of polyps, endoscopic extirpation of pedunculate and sessile/flat polyps up to size $20 \mathrm{~mm}$ and rate of extirpated polyps recovered $[9,11]$.

The limitations of this study were its retrospective nature, performance in just one center, and variation in numbers of colonoscopies per colonoscopist.

\section{Conclusion}

The ADR of the tertiary referral center under study from January 2016 to June 2017 was in line with recommendations of the joint ACG/ASGE Task Force on Quality in Endoscopy [3]. ADR was related to patient age and sex but there was no relationship with the colonoscopists. There was limited variation in ADR among individual colonoscopists, most likely because of their similar training, experiences and awareness of colonoscopy quality guidelines.

Colonoscopy centers should seek to maintain ADR at levels equal to, or higher than, those recommended by consistent and diligent application of all the colonoscopy quality factors, such as patient bowel preparation, CIR and withdrawal time. ADR evaluation should be performed frequently and accompanied by open discussion amongst colonoscopists about the reasons for variations, if any, from previous ADR determinations.

\section{Competing interests}

None

\section{References}

[1] Zauber AG, Winawer S], O'Brien M] et al. Colonoscopic polypectomy and long-term prevention of colorectal-cancer deaths. N Engl J Med 2012; 366: 687-696

[2] Rex DK, Johnson DA, Anderson JC et al. American College of Gastroenterology guidelines for colorectal cancer screening 2009 [corrected]. Am J Gastroenterol 2009; 104: 739 - 750

[3] Rex DK, Schoenfeld PS, Cohen J et al. Quality indicators for colonoscopy. Gastrointest Endosc 2014; 81: $31-53$
[4] Corley D, Jensen CH, Marks A et al. Adenoma detection rate and risk of colorectal cancer and death. N Engl J Med 2014; 370: 1298-1306

[5] Kaminski MF, Regula J, Kraszewska E et al. Quality indicators for colonoscopy and the risk of interval cancer. N Engl J Med 2010; 362: $1795-1803$

[6] Kim SE, Paik HY, Yoon $\mathrm{H}$ at al. Sex- and gender-specific disparities in colorectal cancer risk. World J Gastroenterol 2015; 21: 5167-5175

[7] Imperiale TF, Glowinski EA, Juliar BE et al. Variation in polyp detection rates at screening colonoscopy. Gastrointest Endosc 2009; 69: 1288 1295

[8] Floer M, Meister T. Endoscopic improvement of the adenoma detection rate during colonoscopy - where do we stand in 2015? Digestion 2016; 93: $202-213$

[9] Jover R (Coordinador). Guía de Práctica Clínica de Calidad en la Colonoscopia de Cribado de Cáncer Colorrectal. 1. ed. Alicante: Sociedad Española de Endoscopia Digestiva: 2011

[10] Rivero-Sánchez L, Pellisé M. Preparación para colonoscopia. ¿Algún avance significativo en el horizonte? Gastroenterolog Hepatolog 2015; 38: $287-300$

[11] Anderson J, Butterfly L. Colonoscopy: Quality Indicators. Clinical and Translational Gastroenterology 2015; 6: e77

[12] Lee RH, Tang RS, Muthusamy VR et al. Quality of colonoscopy withdrawal technique and variability in adenoma detection rates. Gastrointest Endosc 2011; 74: 128 - 134

[13] Hewett DG, Rex DK. Cap-fitted colonoscopy: a randomized, tándem colonoscopy study of adenoma miss rates. Gastrointest Endosc 2010; 72: $775-781$

[14] East JE, Stavrindis M, Thomas-Gibson S et al. A comparative study of standard vs high definition colonoscopy for adenoma and hyperplastic polyp detection with optimized withdrawal technique. Aliment Pharmacol Ther 2008; 28: 768-776

[15] DeMarco DC, Odstrcil E, Lara LF et al. Impact of experience with a retrograde-viewing device on adenoma detection rates and withdrawal times during colonoscopy: the Third Eye Retroscope study group. Gastrointest Endosc 2010; 71: 542-550

[16] Cardoso D, Botacin M, Mekdessi M. Adenoma Detection Rate Evaluation and Quality of Colonoscopy in the Center-West Region of Brazil. Arq. Gastroenterol 2017: 47

[17] Gohel TD, Burke CA, Lankaala P et al. Polypectomy rate: a surrogate for adenoma detection rate varies by colon segment, gender, and endoscopist. Clin Gastroenterol Hepatol 2014; 12: 1137-1142

[18] Adler A, Wegscheider K, Lieberman D et al. Factors determining the quality of screening colonoscopy: a prospective study on adenoma detection rates, from 12,134 examinations (Berlin colonoscopy project 3, BECOP-3). Gut 2013; 62: 236-241

[19] Abdul-Baki H, Schoen RE, Dean K et al. Public reporting of colonoscopy quality is associated with an increase in endoscopist adenoma detection rate. Gastrointest Endosc 2015; 82: 676-682

[20] Marcondes FO, Dean KM, Schoen RE et al. The impact of exclusion criteria on a physician's adenoma detection rate. Gastrointest Endosc 2015; 82: 668-675

[21] Olivera K. Estudio Observacional de Detección y Características de adenomas colorrectales en el Hospital Nacional Guillermo Almenara Irigoyen [Trabajo de Investigación]. Lima: Universidad Nacional Mayor de San Marcos; 2015

[22] Barreda C, Vila S, Salazar F et al. Adenomas Avanzados en 3,700 Colonoscopias. Rev Gastroenterol Perú 2010; 30-2: 113 -120

[23] Anderson JC, Butterly LF, Goodrich M et al. Differences in detection rates of adenomas and serrated lesions in screening vs surveillance colonoscopies. Clin Gastroenterol Hepatol 2013; 11: 1308-1312

[24] Do A, Weinberg J, Kakkar A et al. Reliability of adenoma detection rate is based on procedural volume. Gastrointest Endosc 2013; 77: 376 380 
[25] Valori RM, Damery S, Gavin DR et al. A new composite measure of colonoscopy: the Performance Indicator of Colonic Intubation (PICI). Endoscopy 01 2018; 50: 40 - 51

[26] The Paris endoscopic classification of superficial neoplastic lesions. Esophagus, stomach, and colon. November 30 to December 1, 2002. Gastrointest Endosc 2003; 58: S3-S43

[27] Van Doorn S, Hazewinkel Y, East JE et al. Polyp Morphology: An Interobserver Evaluation for the Paris Classification Among International Experts. Am J Gastroenterol advance online publication 21.10. 2014: doi:10.1038/ajg.2014.326

[28] Azzoni C, Bottarelli L, Campanini N et al. Distinct molecular patterns based on proximal and distal sporadic colorectal cancer: arguments for different mechanisms in the tumorigenesis. Int J Colorectal Dis 2007; 22: $115-126$

[29] Mishra G. Clinical Review: How to recognize subtle lesions in the coIon. ASGE Leading Edge 2015; 5: 1 - 13
[30] Abdeljawad K, Vemulapalli K, Kahi CH et al. Sessile serrated polyp prevalence determined by a colonoscopist with a high lesion detection rate and an experienced pathologist. Gastrointest Endosc 2015; 81: $517-524$

[31] East JE, Atkin W, Bateman A et al. British Society of Gastroenterology position statement on serrated polyps in the colon and rectum. Gut 2017; 0: 1 - 16

[32] Kim JS, Lee B-I, Choi H et al. Cold snare polypectomy versus cold forceps polypectomy for diminutive and small colorectal polyps: a randomized controlled trial. Gastrointest Endosc 2015; 81: 741 - 747

[33] Britto-Arias M, Waldmann E, Jeschek $P$ et al. Forceps versus snare polypectomies in colorectal cancer screening: ¿are we adhering to the guidelines? Endoscopy 2015; 47: 898-902

[34] O’Connor S, Brooklyn T, Dunckley P et al. High complete resection rate for pre-lift and cold biopsy of diminutive colorectal polyps. Endosc Int Open 2018; 06: E173-E178 